\title{
Damage localisation and severity evaluation of a beam-like timber structure based on modal strain energy and flexibility approaches
}

Received (in revised form): 25th January, 2007

\begin{abstract}
Jianchun Li
received his PhD from the University of Dublin, Ireland in 1993. He is currently a senior lecturer in Faculty of Engineering, University of Technology, Sydney. He has over 20 years extensive research experience crossing different disciplines from aeronautical, mechanical to civil engineering. He has authored or co-authored over 80 scholarly publications of book, journal and conference papers. His current research interests lie in the areas of damage detection of civil engineering structures, smart materials and structures, structural vibration control, dynamic measurement and analysis of buildings and bridge.
\end{abstract}

\section{F.C. Choi}

is currently a PhD candidate in the University of Technology, Sydney. His main research focuses in the area of damage detection of timber structure using vibration-based methods.

\section{Bijan Samali}

is the current Head of Civil, Environmental and Construction Engineering at the University of Technology, Sydney and has a personal chair in Structural Engineering at UTS. He is also the Director of Centre for Built Infrastructure Research at UTS. He has published over 150 technical papers in engineering journals and conference proceedings. His main research interests lie in the general area of structural dynamics including wind and earthquake engineering with special emphasis on structural control, dynamic measurement and analysis of buildings and bridges, and use of smart materials in engineering applications.

\section{Keith Crews}

joined the University of Technology, Sydney in 1993 to establish an education and research programme in Timber Engineering, following ten years in private practice as a Chartered Consulting Structural Engineer. He is currently a professor in the Faculty of Engineering and Deputy Director of the Centre for Built Infrastructure Research. His work involves teaching of various structural design subjects in both the undergraduate and graduate programmes, as well as research and specialist consulting activities. He is the author of over 150 technical reports and papers relating to the use and reliability of structural timber and enjoys an international reputation as a Timber Engineering researcher. His consultancies include research and development and specialist design for numerous government instrumentalities, timber industry companies, developers and consultants.

Correspondence: Jianchun Li, Center for Built Infrastructure Research, Faculty of Engineering, University of Technology, Sydney; Tel: +61 29514 2651; Fax: +61 29514 2633; E-mail: lij@eng.uts.edu.au; Web: http://www.eng.uts.edu.au/ lij

\begin{abstract}
Timber bridges are often exposed to harsh environmental conditions, which, over time, can lead to deterioration resulting from decay, insect attack, weathering, and mechanical damage. In turn, this deterioration may lead to a loss of structural integrity that is detrimental to the structure and its users. Non-destructive evaluation (NDE) techniques provide effective means for assessment of current structural integrity status of given structures. As a global NDE technique, vibration-based damage identification techniques have received increasing attention for structural damage evaluation. Among them, there is a popular and promising damage identification method called the damage index method based on calculating the change of modal strain energy before and after damage. Despite its popularity, however, a systematic investigation on
\end{abstract}


its capability and limitations in locating and quantifying damage is yet to be reported, especially for structures suffering multiple damage. In this paper, after reviewing the current NDE methods, the focus was set on the vibration-based NDE methods, in particular the damage index method. The investigation was based on finite element analysis (FEA) results of a timber beam by which the capability and limitation of the damage index was fully explored. As a result of the investigation, a new hybrid algorithm combining modified damage index (MDI) and change in flexibility algorithms is proposed for damage localisation and severity evaluation. The numerical results indicate that the proposed hybrid algorithms based on MDI method and flexibility have clear advantages in detecting damage locations and evaluating damage severities, especially for multiple damage cases.

Journal of Building Appraisal (2007) 2, 323-334. doi:10.1057/palgrave.jba.2950059

\section{Keywords:}

timber structure, damage detection, non-destructive evaluation, modal strain energy, vibration

\section{INTRODUCTION}

Non-destructive evaluation (NDE) of wood is the science and art of determining the material properties and/or structural capacity of individual members or for an entire timber structure without impairing the member or structure in its usefulness for its intended purpose. Based on scales of the applications, the NDE techniques can be categorised as local or global with each type having advantages and disadvantages that affect its use. Proper application of NDE techniques allows for a more confident assessment of material properties and, in turn, structural integrity and residual capacity.

\section{Local NDE of timber members}

Timber structural elements are susceptible to degradation due to environmental and loading conditions. This degradation weakens the member and can inhibit the performance of the entire structure. A variety of local NDE techniques can be employed to locate damage and decay in timber members in order to maintain structural performance (Emerson et al., 1998).

\section{Visual inspection}

Visual inspection is the simplest NDE technique, and often is the first process in assessing a timber structure such as a bridge. Obvious deficiencies can be easily identified, including external damage, decay, crushed fibres in bearing, creep, or presence of severe splits. Results of visual inspection can be employed to guide further NDE. Besides results being qualitative with variability stemming from differences in visual acuity and training/ experience of personnel, the components with limited access may, however, be susceptible to increased error in the interpretation of visual inspection, and unexposed components cannot be inspected at all.

\section{Stress wave}

An impact on the surface of the material under investigation generates stress waves that propagate at the speed of sound through the material and reflect from external surfaces, internal flaws, and boundaries between adjacent materials. If the material dimensions are 
known, stress wave timing can be used to locate decay in timber members. Since stress waves travel slower through decayed wood than sound wood, the localised condition of a member can be determined by measuring stress wave time at incremental locations along the member. A stress wave will typically attenuate more rapidly in decayed wood than in sound wood (Ross et al., 1997). A common use of stress waves is in determining the modulus of elasticity (MOE) for structural members (Pellerin et al., 1985).

\section{Ultrasonic}

Ultrasonic inspection involves analysis of the characteristics of high frequency $(f>20 \mathrm{kHz})$ stress waves propagating through a material. Ultrasonic inspection techniques have been explored for detecting strength-reducing defects such as knots, slope of grain, and decay in wood members. Primary difficulties associated with ultrasonic inspection of wood members include effective ultrasonic coupling between the transducers and the wood surface, limitations on material dimensions for effective inspection due to the attenuative nature of wood. Since high frequency stress waves attenuate significantly over relatively short distances in wood (particularly for wave propagation across the wood grain), ultrasonic detection of decay and other defects is primarily effective in relatively small regions of wood members (Wilcox, 1988).

\section{Drill resistance}

Drill resistance is a quasi-non-destructive test that has been used to determine density and detect decay in trees and timber in which small diameter $(1.5-3 \mathrm{~mm})$ holes remains in the specimen after testing. Drill resistance devices operate under the premise that resistance to penetration is correlated with material density. The resistance profile can also be used to estimate member density and compares favourably with radiography (Helms and Niemz, 1994). Owing to the invasive nature of the drill resistance technique, and the fact that it provides a very localised measure of density, this technique may be best employed if used in conjunction with other NDE methods that provide qualitative condition assessment (eg visual inspection) or regional condition assessment (eg stress wave or ultrasonic inspection).

\section{Radiography}

Radiography and its more advanced version called computed tomography, which produces a three-dimensional representation of the internal structure of an object, can be used to accurately estimate localised wood density by employing X-rays and gamma rays. Radiography has been used to investigate wood degradation due to fungal attack. The investigation revealed that density-determined radiographically corresponded well to gravimetrically determined density and decay (Bucur et al., 1996). Portability and member access are two major problems for field implementation.

\section{Microwave/ground penetrating radar}

Microwave and millimetre wave inspection techniques involve the propagation of electromagnetic waves from probes (typically antennas) at frequencies ranging from $300 \mathrm{MHz}$ to $300 \mathrm{GHz}$ in dielectric (ie electrically insulating) materials. Microwave inspection of wood has been investigated for assessment of material density, moisture content, and grain angle in automated lumber grading systems. Success has also been reported for detecting localised pockets of decay in standing trees (Miller and Doolittle, 1990). Since electromagnetic waves are sensitive to the presence of moisture, it has been 
suggested that microwave techniques have significant potential for detecting decay in ageing timber structures (Zoughi, 1990). Furthermore, the detection of voids, decay, and determination at the interface between timber bridge decks and asphalt wearing surfaces appears to be a natural extension of current commercial microwave inspection techniques for concrete bridge decks.

\section{Shortcomings of local NDE methods}

Local NDE on individual members provides valuable information about the localised condition of bridge elements. These methods, however, in general, are performed on a much localised scale and the evaluation of an entire structure using these methods can be very time-consuming and inefficient. In addition, more information is required to assess the condition of a large-scale structure such as a bridge as an entity, especially for the areas with no access. Thus, it is very much desirable to have a method of non-destructive testing for timber structures that can identify damage or decay from a global perspective. In this paper, two methods employed for assessing the global condition of a bridge are considered: vibration-based damage detection and diagnostic load testing.

\section{Global NDE for bridge systems}

\section{Diagnostic static load tests}

Diagnostic load tests have been widely used for bridge structural integrity assessment that typically involves relatively small static loads applied to a bridge. They provide valuable insight into the true elastic load-response behaviour of a bridge, but they can only be used to aid in the prediction of the maximum load carrying capacity of the structure. In contrast, larger proof loads may be applied to a bridge to directly determine a structure's safe load-carrying capacity. These methods, however, are costly, time-consuming and may further impair the bridge and jeopardise its integrity.

\section{Vibration-based damage detection}

Damage or fault detection, as determined by changes in the dynamic properties or response of systems has been practised in a qualitative manner, using acoustic techniques. More recently, this subject has received considerable attention in the technical literature where there have been a concerted effort to develop a firmer mathematical and physical foundation for this technology.

The basic idea, however, remains that commonly measured modal parameters (notably frequencies, mode shapes, and modal damping) are functions of the physical properties of the structure (mass, damping, and stiffness). Therefore, changes in the physical properties, such as reductions in stiffness resulting from the onset of cracks or loosening of a connection, will cause detectable changes in these modal properties. Because changes in modal properties or properties derived from these quantities are being used as indicators of damage, the process of modal-based damage detection eventually reduces to some form of a pattern recognition problem. In recent years, many studies for modal-based damage identification have been undertaken using modal parameters. These were covered by Hearn and Testa (1991); Pandey and Biswas (1994); Salawu and William (1995); Stubbs et al. (1995); Li et al. (2005): and Wang et al. (2001).

On the other hand, development of modal-based damage identification in the laboratory or in the field in recent years has created opportunities for damage identification of timber structures. There have been limited studies on damage detection of timber beams and 
timber bridges (Peterson et al., 2001a,b, 2003) in which the method of damage localisation was applied to timber structures. The studies showed the ability of the adopted damage identification algorithm to successfully locate the inflicted damage for single damage cases. The multiple damage scenarios and severity of damage evaluation were, however, not covered in these studies.

In this study, research was undertaken to investigate the capabilities and limitations of different damage detection algorithms, namely the modified damage index method (MDI), the change in flexibility method (CIF) and the hybrid of the two methods, for locating and evaluating inflicted damage in a timber beam. Both single and multiple damage scenarios were considered. A numerical model of a timber beam has been developed using finite element analysis (FEA) as a test case. The extracted modal parameters were used in the calculations and use in all algorithms in this paper.

\section{NUMERICAL MODEL}

\section{Undamaged model}

An analytical beam model was developed using a commercial FEA package, namely ANSYS. The model, illustrated in Figure 1, was constructed based on sawn timber beams, widely available in Australia. The model possesses breath of $45 \mathrm{~mm}$ and depth of $90 \mathrm{~mm}$, respectively, with a span length of $4,500 \mathrm{~mm}$. The beam is of radiata pine timber with MOE of $12,196 \mathrm{~N} / \mathrm{mm}^{2}$ obtained from a four-point bending test. The solid elements (SOLID45) were utilised to model the beam, for which different damage scenarios can be easily introduced. As shown in Figure 1, 41 nodes and 40 elements were used in the model, denoted by numbers with and without italics, respectively. Five flexural mode shapes were extracted from the FE model as shown in Figure 2.

\section{Damaged model}

To investigate existing algorithms and develop new ones for detecting damage in single and multiple locations in a beam-like structure, it is necessary to define damage scenarios. In this paper, five damage cases are considered as described in Table 1. The damage is generated by cutting rectangular openings from the soffit of the beam, located at $2 / 8$, midspan, $5 / 8$ and $6 / 8$ of the span length to simulate pockets of rotten wood. The scenarios were designed to investigate the sensitivities of modal parameters to different location and severity of damage. In the following study, 'M' denotes medium level of damage that contains a cut (or cuts) of $45 \mathrm{~mm}$ (1 per cent of the beam length) along the span and $27 \mathrm{~mm}$ in depth (30 per cent of the beam depth in cross section). A cut of 30 per cent in the beam depth at a cross section is equivalent to 65.7 per cent of loss of the sectional moment of inertia (indicated by 'I'). The configuration of a typical damage inflicted in the

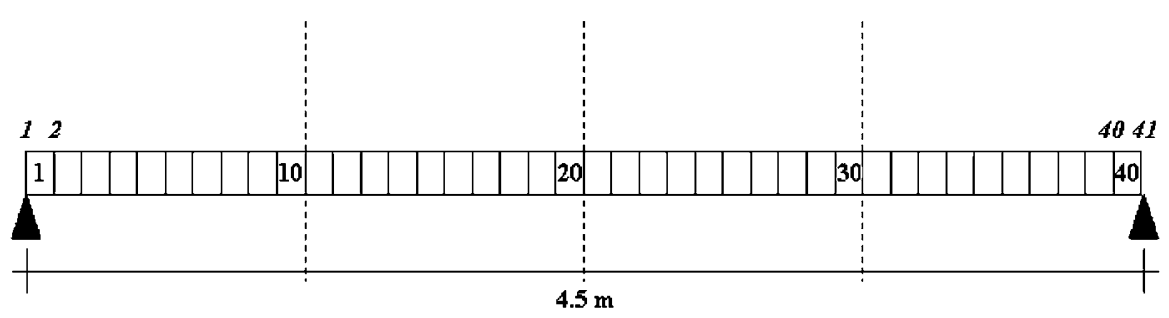

Figure I: Nodes and elements for FE model of the timber beam 


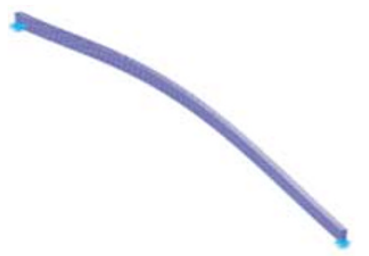

$1^{\text {st }}$ flexural

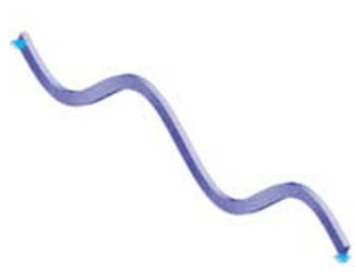

$4^{\text {th }}$ flexural

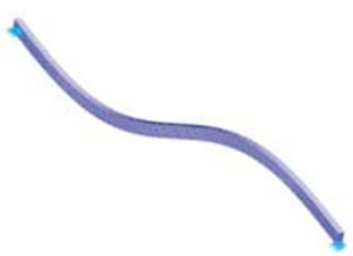

$2^{\text {nd }}$ flexural

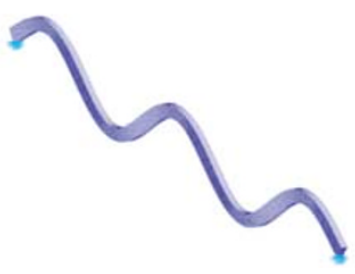

$5^{\text {th }}$ flexural

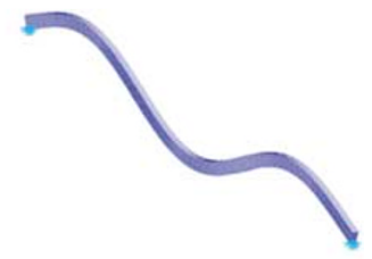

$3^{\text {rd }}$ flexural

Figure 2: The first five mode shapes of the timber beam

Table I: Dimensions of inflicted damage

\begin{tabular}{lllll}
\hline Damage case & $\begin{array}{l}\text { Location per 8th of the } \\
\text { span length }\end{array}$ & Width $(\mathbf{m m})$ & Depth $(\mathbf{m m})$ & \% reduction of 'l' \\
\hline 4M & 4 & 45 & 27 & 65.7 \\
4M6M & 4,6 & 45 & 27 & 65.7 \\
4M5M6M & $4,5,6$ & 45 & 27 & 65.7 \\
2M4M5M6M & $2,4,5,6$ & 45 & 27 & 65.7 \\
\hline
\end{tabular}

beam is shown in Figure 3, starting from the soffit of the beam. List of damage scenario cases and their corresponding dimensions is given in Table 1.

\section{DAMAGE DETECTION}

\section{Modified damage index}

The damage index method developed by Stubbs et al. (1995) was selected and modified (Li et al., 2005) to detect incidences of multiple damage. The method pertaining to damage localisation is based on the relative differences in modal strain energy between an undamaged structure and that of the damaged structure. The modal strain energy utilises 2nd derivative of mode shape, that is mode shape curvature, and the algorithm used to calculate the damage index for the $j$ th element and the $i$ th mode, $\beta_{i j}$, is given below.

$$
\beta_{i j}=\frac{\left[\int_{j}\left\{\phi_{i}^{\prime / *}(x)\right\}^{2} d x+\int_{0}^{L}\left\{\phi_{i}^{\prime / *}(x)\right\}^{2} d x\right] \int_{0}^{L}\left\{\phi_{i}^{\prime \prime}(x)\right\}^{2} d x}{\left[\int_{j}\left\{\phi_{i}^{\prime \prime}(x)\right\}^{2} d x+\int_{0}^{L}\left\{\phi_{i}^{\prime \prime}(x)\right\}^{2} d x\right] \int_{0}^{L}\left\{\phi_{i}^{\prime / *}(x)\right\}^{2} d x}
$$




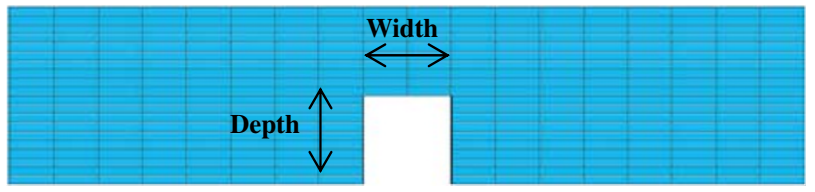

Figure 3: Configuration of damage cases

To account for all available modes, $N M$, the damage indicator value for a single element $j$ is given as

$$
\beta_{j}=\frac{\sum_{i=1}^{N M} N_{i j}}{\sum_{i=1}^{N M} \text { Denom }_{i j}}
$$

where $N u m_{i j}$ is the numerator of $\beta_{i j}$ and Denom $i j$ the denominator of $\beta_{i j}$ in Equation (1), respectively.

The derivation of Equation (1) is discussed in more detail in authors previous publication (Li et al., 2005). It should be noted that in Equation (1), the terms $\varphi^{\prime \prime}(x)$ are normalised vectors of mode shape curvature coordinates of a one-dimensional system that is different from the original damage identification method. The asterisk denotes the same for damaged cases. The reason for mode shape curvature normalisation is that the values of mode shape curvature are dependant on the order of each individual mode shape. Instead of reflecting the changes in the curvature due to damage, the summation (from Equation 2) without normalising mode shape curvatures will distort the damage index in favour of higher modes, which results in false damage identifications.

Transforming the damage indicator values into the standard normal space, the normalised damage index $Z_{j}$ is obtained:

$$
Z_{j}=\frac{\beta_{j}-\mu_{\beta \mathrm{j}}}{\sigma_{\beta \mathrm{j}}}
$$

where $\mu_{\beta j}$ is the mean of $\beta_{j}$ values for all $j$ elements and $\sigma_{\beta j}$ the standard deviation of $\beta_{j}$ for all $j$ elements. A judgment-based threshold value is selected and used to determine which of the $j$ elements are possibly damaged which in real applications is left to the user to define based on what level of confidence is required for localisation of damage within the structure.

The severity of damage in the $j$ th member can be related to damage indicator $\beta_{j}$ using the following expression

$$
\alpha_{j}=1-\frac{1}{\beta_{j}}
$$

where $\alpha_{j}$ is the severity estimator. The severity estimation using the above equation is, however, inconsistent and can produce large errors. This is partly due to crude assumptions during derivation as well as the fact that the change of mode shape curvature is also a function of location.

\section{Changes in flexibility}

The flexibility matrix in the form of modal parameters is presented in Equation (5) (Pandey and Biswas, 1994) in which mode shapes are mass normalised. 


$$
F=\Phi \Omega^{-1} \Phi=\sum_{i=1}^{n} \frac{1}{\omega_{i}^{2}} \phi_{i} \phi_{i}^{T}
$$

where $\omega_{i}$ is the $i$ th modal frequency, $n$ is the number of degrees of freedom and $F$ is the flexibility matrix. In practice, it is relatively difficult to obtain higher modes, thus resulting in an approximate flexibility matrix with only a few lower modes.

The CIF $\Delta$ is defined as the difference of flexibility between the undamaged $\left(F_{u}\right)$ and damaged $\left(F_{d}\right)$ structure as given by

$$
\Delta=F_{u}-F_{d}
$$

For each degree of freedom $j$, let $\left(\delta_{j}\right)_{\max }$ be the maximum absolute value of the elements $\left(\delta_{i j}\right)$ in the corresponding $i$ th column of $\Delta$ as shown in Equation (7).

$$
\left(\delta_{j}\right)_{\max }=\max _{i}\left|\delta_{i j}\right|
$$

The quantity $\left(\delta_{j}\right)_{\max }$, as the measure of CIF for each measurement location, was used to detect and locate damage in a structure.

\section{Hybrid of MDI and CIF}

The hybrid of MDI and CIF (referred as HMC in the following discussions) was proposed based on the fact that both damage identification algorithms were unable to properly estimate the severity of damage. The MDI can predict the damage locations well and CIF is used as weighting function to modify estimation of damage evaluation from MDI. The formulation for the HMC is shown in Equation (8). It should be noted that the HMC algorithm has been calibrated against the severe single damage cases at different locations using the 3-dimensional Gaussian non-linear regression. The output of the severity is in terms of percentage of depth of damage from the soffit of the beam, which if necessary, can be converted to percentage of loss of 'I'.

$$
H M C=Z_{j}\left(\delta_{j}\right)_{\max }
$$

\section{RESULTS AND DISCUSSION}

In the following results, the statistically normalised damage indicator values $\left(Z_{j}\right)$ and changes in flexibility values for each of the damage cases are plotted against the span length of the beam for the MDI and CIF methods, respectively. While for the HMC method, the estimation of damage severity is presented in terms of the percentage of depth loss in cross-section. The actual damage locations are indicated with dashed lines in all figures.

\section{Modified damage index}

As seen in Figures $4 a-d$, the MDI is capable of detecting all damage locations for the medium damage cases as listed in Table 1 . These results show that the method is good in locating damage accurately. It is worth noting that the value of $Z_{j}$ gets smaller as multiple damage is introduced. This may be due to the fact that $\beta_{j}$ at each measurement location is getting smaller along the span length as more damage is being inflicted. This feature has distorted the results of MDI method in directly estimating damage severity in the structure. Nevertheless, the value of $Z_{j}$ does provide an indication of the probability of the 
existence of damage. For instance, in Figure 4d, all the peaks showed a similar probability that there is damage in that position. Based on this observation, it is possible to estimate that these damages have relatively similar severity, but not the absolute values. The MDI method presented in this paper is unable to provide meaningful results in order to estimate damage severity from Equation 4, and hence not reported.

\section{Change in flexibility}

The changes in flexibility for single and multiple damage scenarios are plotted in Figures $5 \mathrm{a}-\mathrm{d}$. From these figures, there is a general trend that the change in the flexibility matrix starts with zero at the supports and increases as it moves towards the midspan of the beam. It is apparent that a change of slope sign occurs at each damage location. For example, in Figure 5a (a single damage case), a change of slope happens at the midspan, where the damage is located. For multiple damage location cases, as shown in Figures $5 \mathrm{c}$ and $\mathrm{d}$, the damage at location $6 / 8$ of the span length was, however, not identified as there was no change of slope sign. It is deduced that the CIF method is capable to locate single damage location and even two damage locations. It, however, has difficulty to identify all damage locations when it comes to multiple damage scenarios. For the estimation of severity, the CIF method is not recommended as it is highly influenced by the geometric locations and boundary conditions. This can be demonstrated in Figure 5b, whereby difference between the two peaks is relatively large but in fact they have the same damage severity.
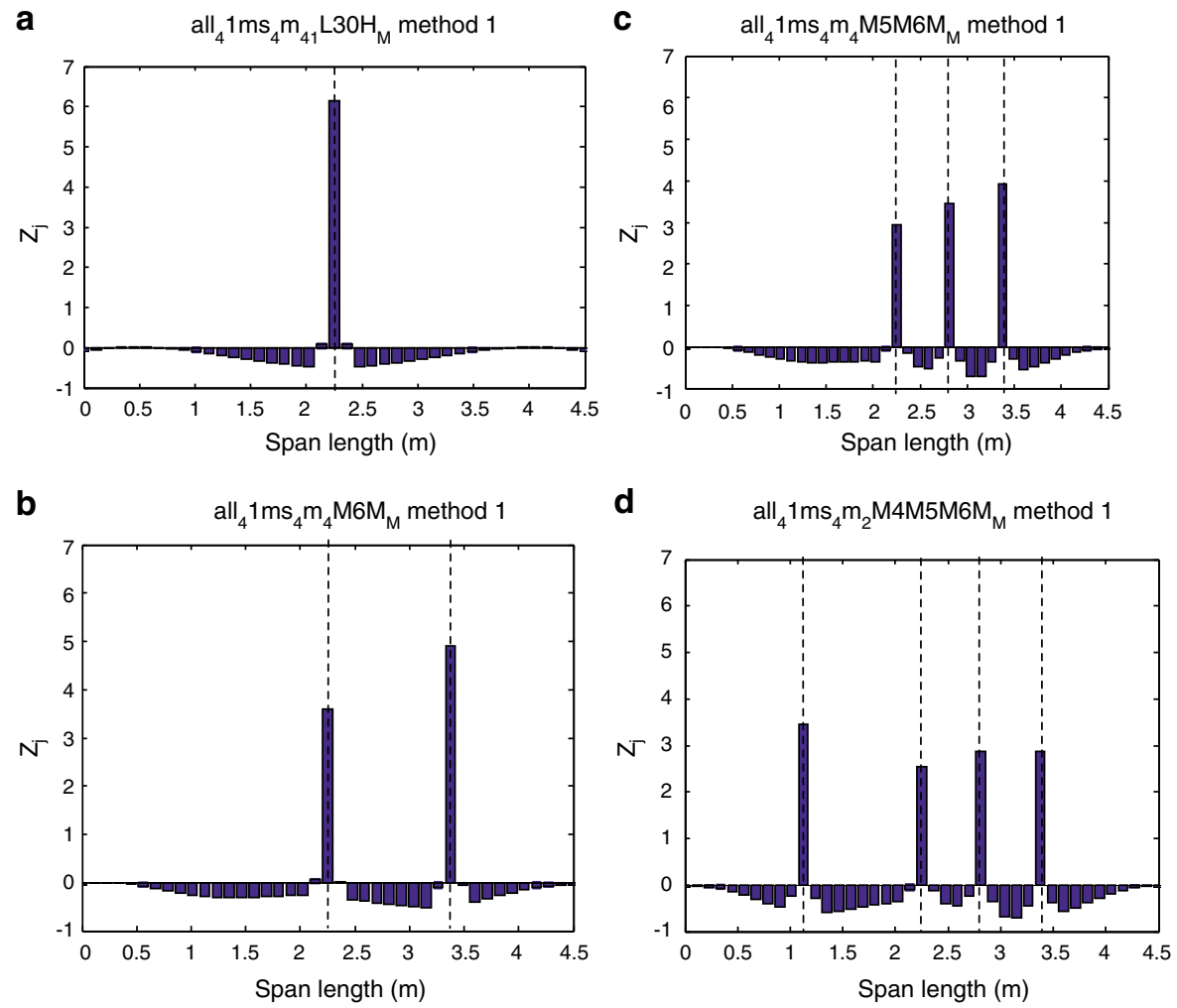

Figure 4: Identification of damage locations using the MDI method with only the first two modes: (a) Damage case 4M, (b) Damage case 4M6M, (c) Damage case 4M5M6M, (d) Damage case 2M4M5M6M 

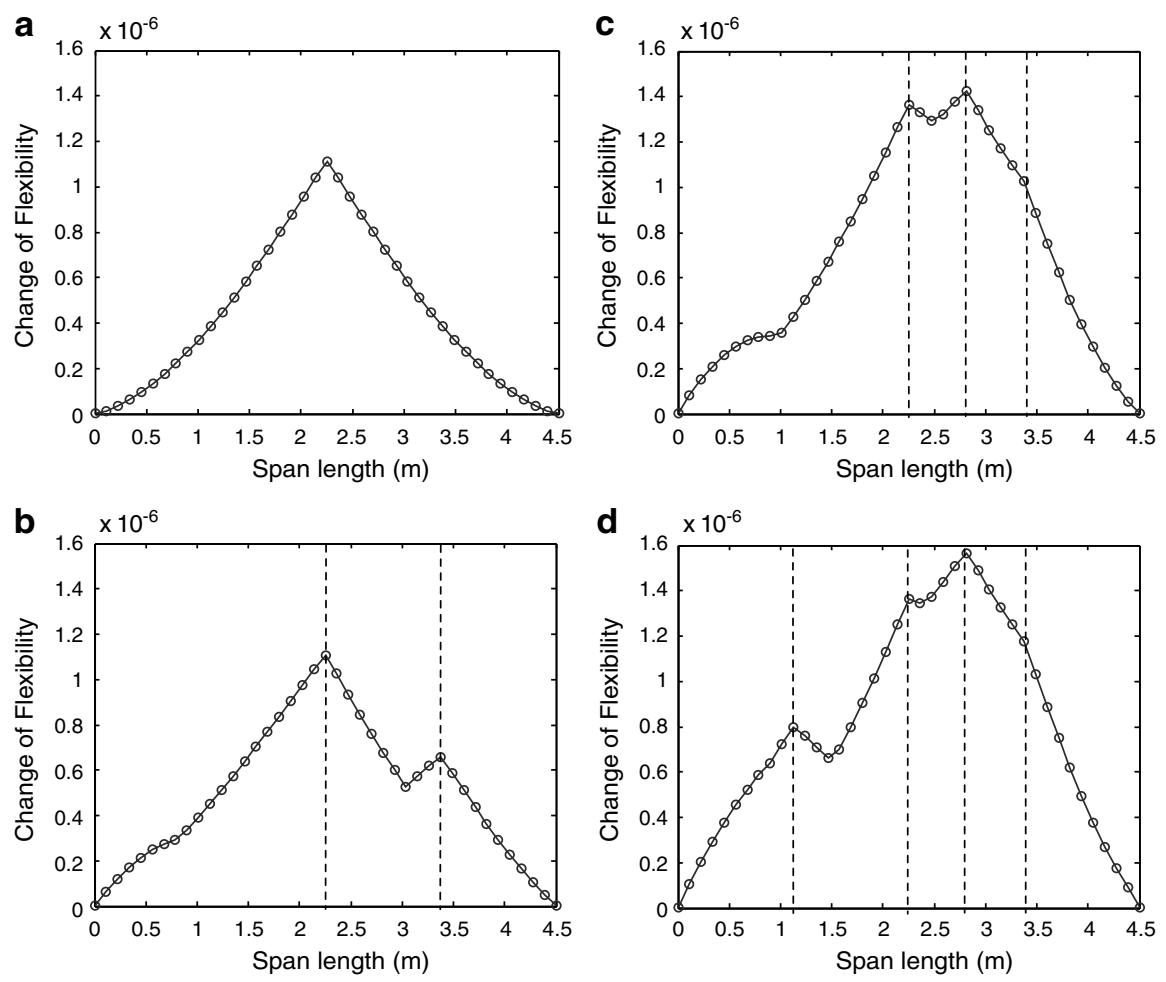

Figure 5: Identification of damage locations using the CIF method with only the first two modes: (a) Damage case 4M, (b) Damage case 4M6M, (c) Damage case 4M5M6M, (d) Damage case 2M4M5M6M

\section{Hybrid of MDI and CIF}

As noted in the two preceding sections, the MDI and CIF methods are unable to estimate the severity of damage individually. In order to overcome this problem, the HMC method is proposed. All the results of single and multiple damage scenarios are illustrated in Figures 6a-d. For the single damage case, as shown in Figure 6a, it is obvious that the method is correctly pinpointing the location of damage, and at the same time precisely estimates the damage severity (30 per cent of loss of section height from the soffit of the beam). As the method was applied to multiple damage cases, the estimation of damage severity was quite acceptable in addition to precise identification of the damage locations. The slight setback with respect to accuracy in the multiple damage scenarios can be easily overcome by applying a weighting factor that would take into consideration geometric location and boundary condition effects. The newly proposed HMC method is found to be capable of detecting damage locations and estimating damage severity with a reasonable level of confidence for single and multiple damage scenarios.

\section{CONCLUSION}

A variety of NDE techniques are available for determining the condition of an ageing timber bridge. The goal of this ongoing research is to develop a global-based NDE technique that provides a more effective prediction of timber bridge condition and capacity.

In this paper, a few global NDE techniques, namely, some vibration-based NDE techniques have been investigated. A single and multiple damage scenarios were selected 
a

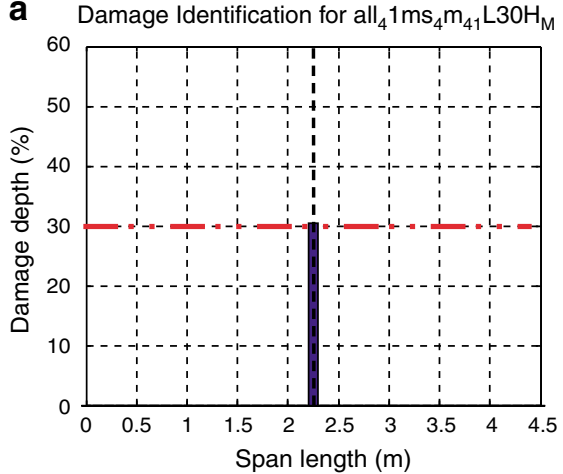

b Damage Identification for all $1 \mathrm{~ms}_{4} \mathrm{~m}_{4} \mathrm{M}_{6} \mathrm{M}_{\mathrm{M}}$

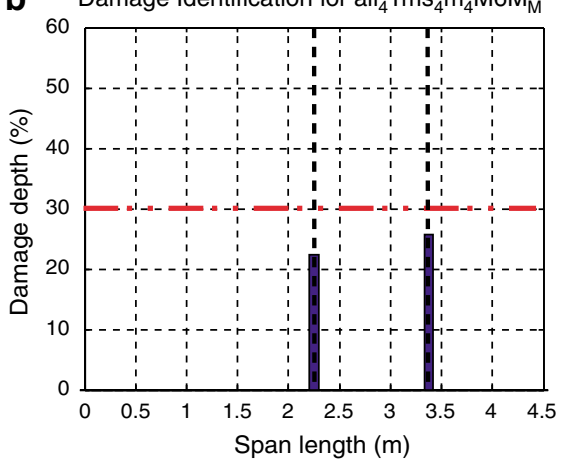

C Damage Identification for all $1 \mathrm{~ms}_{4} \mathrm{~m}_{4} \mathrm{M}_{5} \mathrm{M} 6 \mathrm{M}_{\mathrm{M}}$

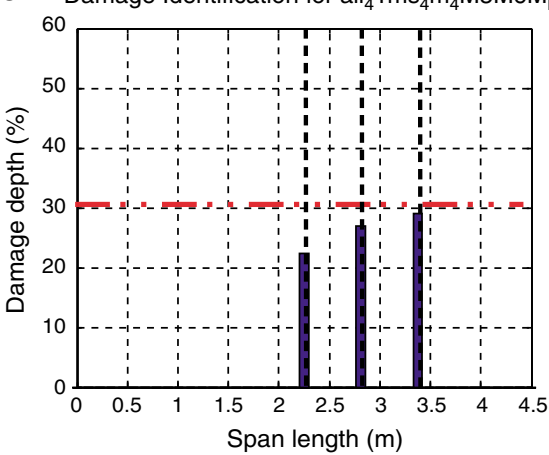

d Damage Identification for all $_{4} 1 \mathrm{~ms}_{4} \mathrm{~m}_{2} \mathrm{M} 4 \mathrm{M} 5 \mathrm{M} 6 \mathrm{M}_{\mathrm{M}}$

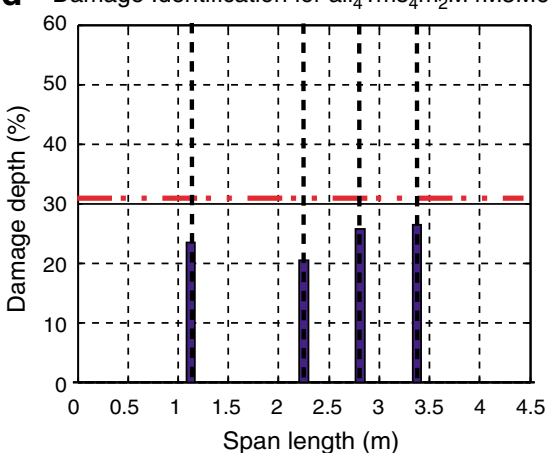

Figure 6: Estimation of damage severity using the HMC method with only the first two modes: (a) Damage case 4M, (b) Damage case 4M6M, (c) Damage case 4M5M6M, (d) Damage case 2M4M5M6M

to study the feasibility of existing and a newly extended algorithm in detecting location and estimating severity of damage. The MDI method is proved to be a good tool to detect locations of damage in structures, although the severity of damage cannot be quantitatively evaluated. Nevertheless, the method still provides qualitative estimation of the severity of damage for single and multiple damage scenarios. The well-known CIF method, utilising natural frequency and mode shape, also has the potential to be used to locate damage, but it may only be of use for one or two damage location scenarios. With the newly proposed HMC method, detection and evaluation of multiple damage locations and severities are made possible with a reasonable level of precision, even though it underestimates the severity of damage for multiple damage cases. This shortcoming can be easily overcome by using a weighting factor to calibrate the predicted damage, such that it is similar to the actual damage. It is therefore concluded, based on the research presented in this paper, that the HMC method is a viable tool to be used for assessment of timber bridges. In addition, it has also created new opportunities for more developments in the area of damage identification using modal-based data.

Combining global and local NDE methods, it is feasible to effectively and reliably pinpoint localised damage in individual members and estimate the effects of this damage on the overall capacity of the structural system with time and cost efficiencies.

\section{Acknowledgments}

The authors wish to thank the Centre for Built Infrastructure Research (CBIR), the Faculty of Engineering, University of Technology, Sydney for its support of this project. 


\section{References}

Bucur, V., Garros, S., Navarrete, A., de Troya, M.T. and Guyonnet, R. (1996) 'Kinetics of wood degradation by fungi with X-ray microdensitometric technique', Proceedings of the 10th International Symposium on Nondestructive Testing of Wood, Presses Polytechniques et Universitaires Romandes, pp. 209-215.

Emerson, R.N., Pollock, D.G., Kainz, J.A., Fridley, K.J., McLean, D.I. and Ross, R.J. (1998) 'Nondestructive evaluation techniques for timber bridges', Proceedings of the 1998 World Conference on Timber Engineering (WCTE), Lausanne, Switzerland, pp. 670-677.

Hearn, G. and Testa, R.B. (1991) 'Modal analysis for damage detection in structures', Journal of Structural Engineering ASCE, 117(10), 3042-3063.

Helms, D. and Niemz, P. (1994) 'New applications of the drill resistance method for quality evaluation of wood and wood products', Proceedings of the 9th International Symposium on Nondestructive Testing of Wood, 22-24th September, 1993, Washington State University, Madison, WI, pp. 95-102.

Li, J., Samali, B., Choi, F.C. and Dackermann, U. (2005) 'Damage identification of timber bridges using vibration based methods', Proceedings of the 11th Asia-Pacific Vibration Conference, November 23-25, Langkawi, Malaysia, pp. 662-668.

Miller, W.F. and Doolittle, J.A. (1990) 'The application of ground-penetrating radar to detection of internal defect in standing trees', Proceedings of the 70, International Nondestructive Testing of Wood Symposium, September 27-29, 1989, Washington State University, Madison, WI, pp. 263-274.

Pandey, A.K. and Biswas, M. (1994) 'Damage detection in structures using changes in flexibility', Journal of Sound and Vibration, 169(1), 3-17.

Pellerin, R.F., DeGroot, R.C. and Esenther, G.R. (1985) 'Nondestructive stress wave measurements of decay and termite attack in experimental wood units', Proceedings of the 5th NondestructiveTesting of Wood Symposium, September 9-11, 1985, Washington State University, Pullman, WA, pp. 319-352.

Peterson, S.T., McLean, D.I., Symans, M.D., Pollock, D.G., Cofer, W.F., Emerson, R.N. and Fridley, K.J. (2001a) 'Application of dynamic system identification to timber beams: I', Journal of Structural Engineering, 127(4), 418-425.

Peterson, S.T., McLean, D.I., Symans, M.D., Pollock, D.G., Cofer, W.F., Emerson, R.N. and Fridley, K.J. (2001b) 'Application of dynamic system identification to timber beams: II', Journal of Structural Engineering, 127(4), 426-432.

Peterson, S.T., McLean, D.I. and Pollock, D.G. (2003) 'Application of dynamic system identification to timber bridges', Journal of Structural Engineering, 129(1), 116-124.

Ross, R.J., DeGroot, R.C., Nelson, W.J. and Lebow, P.K. (1997 'The relationship between stress wave transmission characteristics and the compressive strength of biologically degraded wood', Forest Products Journal, 47(5), 89-93.

Salawu, O.S. and Williams, C. (1995) 'Bridge assessment using forced-vibration testing', Journal of Structural Engineering ASCE, 121(2), 161-173.

Stubbs, N., Kim, J.T. and Farrar, C.R. (1995) 'Field verification of a non-destructive damage localization and severity estimation algorithm', Proceedings of the 13th International Modal Analysis Conference, Nashville, TN, USA, pp. 210-218.

Wang, B.S., Liang, X.B., Ni, Y.Q. and Ko, J.M. (2001) 'Comparative study of damage indices for long-span bridges', Proceedings of IMAC-XIX, Hyatt Orlando, Kissimmee, Florida, USA, pp. 1374-1380.

Wilcox, W.W. (1988) 'Detection of early stages of wood decay with ultrasonic pulse velocity', Forest Products Journal, 38(5), 68-73.

Zoughi, R. (1990) 'Microwave nondestructive testing: theories and applications', International Advances in Nondestructive Testing, 15, 225-288. 